\title{
Introduction/overview on clinical registries
}

\author{
D D Gladman, A Menter
}

Ann Rheum Dis 2005;64(Suppl II):ii101-ii102. doi: 10.1136/ard.2004.030825

$\mathrm{P}$ atient registries have become an important instrument in epidemiological studies in chronic disease. There are several types of registry (table 1). Administrative registries have been developed to identify patients with particular conditions, and these are then used in epidemiological studies to identify prevalence of certain conditions. For administrative registries, a limited amount of primarily demographic information is required as the purpose is only to identify patients rather than to learn as much as possible about an individual patient. Such registries exist in Europe, where patient information is recorded in common registries at each encounter with a physician or a healthcare facility. ${ }^{1-3}$ Such registries have been used to identify associations between the primary disease and other complications such as the development of cancer among patients with psoriasis. ${ }^{4}$

Clinical registries have been developed specifically for drug trials. Some registries have been set up to identify patients who might be suitable for drug trials, whereas others have been developed for the management of the drug trial itself. Registries have also been set up as a surveillance mechanism to follow patients treated with particular medications. ${ }^{5}$ For the latter type of registry, more than simple demographic information, such as previous medications and level of disease activity, is gathered for individual patients. ${ }^{6}$

For a longitudinal observational cohort much more detailed information is required. Here the registry includes not only demographic and drug information, but also a full description of each patient's disease and its course. This allows determination of disease progression, as well as recognition of new disease features, potential side effects, and drug interactions among individual therapies. Such a registry must be comprehensive and based on a robust computer database. Registries based on longitudinal observational cohorts have been developed in rheumatoid arthritis, ${ }^{7}$ systemic lupus erythematosus, ${ }^{89}$ and psoriatic arthritis, ${ }^{10}$ and are under development for psoriasis, particularly relating to biological therapies. These databases have provided important information based on new observations as well as outcomes of patients with these conditions. For a longitudinal observational cohort to be of maximal benefit, another "holy grail" needs to be transcended, namely repeated query, under institutional review board approved conditions, of basic questions related to disease status, effect of environment on disease, response to treatment, side effects, etc, about the cohort at periodic intervals via the internet. From this, important observations of natural history, development of comorbidities such as other autoimmune mediated diseases, etc, can be generated and utilised

$$
\begin{aligned}
& \text { Table } 1 \text { Purpose of registries } \\
& \text { - Administrative registry } \\
& \text { - Registry for clinical trials } \\
& \text { - Registry for longitudinal observational studies } \\
& \text { - Registry for genetic studies }
\end{aligned}
$$

to begin the ultimate quest-use of genotype to predict lifetime risk of disease, response to treatment and therewith knowledge based preventive intervention, where possible.

More recently, there has been great interest in genetic predisposition to disease. The advent of genome scans provides a unique opportunity to identify susceptibility genes. Gene chip technology is further helps identify genes associated with disease, and through proteomics, gene function is being determined. However, these approaches require large numbers of patients and families. Collection of the material, both clinical and biological, requires the development of adequate registries and databases. Cooperation among various centres is advisable, and comparison of samples from different patient cohorts is desirable. In 1994, Menter developed a comprehensive National Psoriasis Gene Bank in Dallas, TX, in cooperation with a patient advocacy group, the National Psoriasis Foundation. ${ }^{11}$ This led to the development of the International Psoriasis Genetics Consortium, the first efforts of which have led to the important finding of multiple susceptibility genes, using a cohort of 942 affected sib pairs.

A registry requires both the collection of clinical and laboratory information at a patient encounter and a database to record this information. Thus, a standardised protocol is required, which is administered to all patients at the encounter, and is then entered into the database. Information can subsequently be obtained from the database and analysed using a statistical package. Cancer registries have been operating for some time in many countries and have been used to derive multicentre trials as well as description of tumours and prognostic factors. ${ }^{12}{ }^{13}$ For genetics based registries, details of family members also have to be entered, not just using a questionnaire but by direct physician-patient contact, history taking, and clinical evaluation. ${ }^{11}$

\section{SPECIAL CONCERNS IN PSORIATIC ARTHRITIS REGISTRIES}

Psoriatic arthritis may be more complicated. Here both skin and joint manifestations occur, and it is still unclear whether the same pathogenic mechanisms are responsible for both. Patients are being followed by both rheumatologists and dermatologists, and at present, few sites have close collaboration between the two specialties. Thus development of large multinational databases required to identify susceptibility genes and their interactions is crucial. Since it is desirable to collect information on large numbers of patients from different centres, it is important to standardise the information collected and develop standardised methods/ tools for data collection at each site. For psoriatic arthritis and psoriasis registries similar information should be collected. Although the exact database used in each centre is not important, it is vital that the same variables are collected and labelled similarly so that when data are transferred to a statistical platform all items labelled similarly could be easily collated and analysed. To do this, it is crucial to ascertain that the information is collected in the same way. 
Thus, reliable and reproducible measures of joint disease activity and damage, as well as skin disease activity and severity, must be used at each centre and recorded in a similar manner in the registry.

Collaboration among rheumatologists and dermatologists is essential for the development of the assessment tools and for testing their validity and assuring their reliability. Merely relying on anecdotal evidence of a personal or family history of skin and joint involvement without a full dermatological and rheumatological evaluation is futile. Thus, at the time of initial entry into the database, the patient's joint disease may be in remission, making the dermatological assessment without the availability of laboratory and radiological data of joint disease difficult and vice versa for psoriatic skin disease. Therefore, careful record keeping of both skin and joint disease and cooperation between the two specialties, as discussed above, is crucial. Laboratory measures must also be performed reliably at each site and recorded in a similar manner. Variables collected should be consistent and accurate. One very important feature of the registry and its database is the ability to transfer the data to a statistical program where the data can be analysed. For this reason the actual database used is not important, but it is essential that mechanisms for downloading the information to a common statistical package are in place and are reliable and accurate.

Thus, prior to developing common registries for psoriatic arthritis, interested individuals should get together and ensure that common information is collected appropriately. Such an effort is currently underway through the Group for Research and Assessment of Psoriasis and Psoriatic Arthritis (GRAPPA).

\section{Authors' affiliations}

D D Gladman, University of Toronto, Toronto Western Research Institute, Psoriatic Arthritis Program, University Health Network, Centre for Prognosis Studies in the Rheumatic Diseases, Toronto Western Hospital, Toronto, Ontario, Canada
A Menter, Division of Dermatology, Baylor University Medical Center, Dallas, TX, USA

Correspondence to: Dr D Gladman, Toronto Western Hospital, 399 Bathurst St ECW 5-034B, Toronto, Ontario, M5T 2S8, Canada; dafna. gladman@utoronto.ca

\section{REFERENCES}

1 Aho K, Kaipiainen-Seppanen O, Heliovaara M, Klaukka T. Epidemiology of rheumatoid arthritis in Finland. Semin Arthritis Rheum 1998;27:325-34.

2 Bjornadal L, Baecklund E, Yin L, Granath F, Klareskog L, Ekbom A. Decreasing mortality in patients with rheumatoid arthritis: results from a large population based cohort in Sweden, 1964-95. J Rheumatol 2002;29:906-12.

3 Shbeeb M, Uramoto KM, Gibson LE, O'Fallon WM, Gabriel SE. The epidemiology of psoriatic arthritis in Olmsted County, Minnesota, USA, 19821991. J Rheumatol 2000;27:1247-50.

4 Aubin F, Puzenat E, Arveux P, Louvat P, Quencez E, Humbert P. Genital squamous cell carcinoma in men treated by photochemotherapy. A cancer registry-based study from 1978 to 1998. Br J Dermatol $2001 ; 144: 1204-6$.

5 Matteson EL, Hickey AR, Maguire L, Tilson HH, Urowitz MB. Occurrence of neoplasia in patients with rheumatoid arthritis enrolled in a DMARD Registry. Rheumatoid Arthritis Azathioprine Registry Steering Committee. J Rheumatol $1991 ; 18: 809-14$.

6 Silman A, Symmons D, Scott DG, Griffiths I. British Society for Rheumatology Biologics Register. Ann Rheum Dis 2003;62:ii28-ii29.

7 Wolfe F, Hawley DJ. The longterm outcomes of rheumatoid arthritis: work disability: a prospective 18 year study of 823 patients. J Rheumatol 1998;25:2108-17.

8 Farewell VT, Lawless JF, Gladman DD, Urowitz MB. Tracing studies and analysis of the effect of lost-to-followup on mortality estimation from patient registry data. J R Stat Soc Ser C Appl Stat 2003;52:445-56.

9 Alarcon GS, McGwin G Jr, Sanchez ML, Bastian HM, Fessler BJ, Friedman AW, et al. Systemic lupus erythematosus in three ethnic groups. XIV. Poverty, wealth, and their influence on disease activity. Arthritis Rheum 2004;51:73-7.

10 Gladman DD, Farewell VT. Progression in psoriatic arthritis: role of time varying clinical indicators. J Rheumatol 1999;26:2409-13.

11 Tomfohrde J, Silverman A, Barnes R, Fernandez-Vina MA, Young M, Lory D, et al. Gene for familial psoriasis susceptibility mapped to the distal end of human chromosome 17q. Science 1994;264:1141-5.

12 Church J, Kiringoda R, LaGuardia L. Inherited colorectal cancer registries in the United States. Dis Colon Rectum 2004;47: 674-8, Epub 25 Mar 2004.

13 Baxter NN, Virnig BA, Durham SB, Tuttle TM. Trends in the treatment of ductal carcinoma in situ of the breast. J Natl Cancer Inst 2004;96:443-8. 